\title{
HAEMATOLOGICAL PARAMETERS IN ALCOHOLICS - EARLY DETECTION
}

\author{
Sneha Shetty1, Balachandra Shetty², U. Vivekananda Reddy33, Anupama $N^{4}$, Bhagyalakshmi $K^{5}$
}

${ }^{1}$ Associate Professor, Department of Physiology, KMC, Mangalore, Manipal University.

${ }^{2}$ Professor, Department of Medicine, AJIMS, Mangalore.

${ }^{3}$ Assistant Professor, Department of Medicine, AJIMS, Mangalore.

${ }_{4}^{4}$ Associate Professor, Department of Physiology, KMC, Mangalore, Manipal University.

5 Professor, Department of Physiology, KMC, Mangalore, Manipal University.

ABSTRACT
BACKGROUND
Alcohol consumption is known for morbidity and mortality, being a serious health hazard of the world.
Aim - The present study was aimed to describe incidence and type of anaemia in alcoholics.

\section{MATERIAL AND METHODS}

The present prospective cross sectional study included about 500 individuals comprised of 185 habitual consumers of alcohol and 315 non-consumers that served as controls. A questionnaire was given to all the subjects to determine the amount of alcohol consumed daily and the duration after which their blood samples were taken. Subjects who consumed at least 4 bottles (of both beer and local gin)/day for a period of at least 5 years were designated as consumers and non-alcoholic drinks consumers were designated as control. Healthy subjects with the age ranging between 19-50 years were included in this study. About $5.0 \mathrm{~mL}$ blood sample from each subject was collected into $\mathrm{K}_{3}$ EDTA anticoagulant bottles and were analysed automatically for haematological parameters using an autoanalyser (Sysmex KN-21N).

\section{RESULTS}

The mean haemoglobin was $10.46 \mathrm{~g} \%$ among alcoholics and $12.31 \mathrm{~g} \%$ among non-alcoholics. $75 \%$ of the alcoholics had pallor. The peripheral blood smear showed all types of anaemia. Normocytic normochromic anaemia was present in $34 \%$ of patients followed by macrocytic hypochromic anaemia (26\%). Microcytic anaemia was present in 15\% patients. Dimorphic anaemia was present in $17 \%$. However, even in non-alcoholics $7 \%$ of patients also showed normocytic normochromic anaemia. $12 \%$ of non-alcoholics showed microcytic hypochromic anaemia.

\section{CONCLUSION}

The present study showed that increased consumption of alcohol has harmful effects such as severe infections which may lead to bone marrow malfunctioning. Early detection of haematological changes in alcoholics and treating them can prevent further complications and helps in reducing the morbidity and mortality.

\section{KEYWORDS}

Alcohol Consumption, Microcytic Anaemia, Normocytic Normochromic Anaemia.

HOW TO CITE THIS ARTICLE: Shetty S, Shetty B, Reddy UV, et al. Haematological parameters in alcoholics - early detection. J. Evolution Med. Dent. Sci. 2016;5(86):6367-6370, DOI: 10.14260/Jemds/2016/1440

\section{BACKGROUND}

Alcoholic beverages have been related with human civilisation since ancient times, and today, alcohol is abundant, with constantly changing patterns of alcohol intake around the world.[1] The effect of alcohol consumption on health outcome is multifaceted and multidimensional.[1] Research has contributed considerably to our understanding of the relation of drinking to specific disorders, It is estimated that $3.5 \%$ of the global burden of disease is attributable to alcohol, which accounts for as much death and disability as tobacco and hypertension.[2,3] Early detection of excessive alcohol use is very important due to its harmful effects on a human organism and a person's psychosocial life.

Financial or Other, Competing Interest: None.

Submission 20-09-2016, Peer Review 13-10-2016,

Acceptance 20-10-2016, Published 25-10-2016.

Corresponding Author:

Dr. Sneha Shetty,

Associate Professor, Physiology,

Kasturba Medical College,

Bejai, Mangalore-575004

E-mail: sneha.shetty@manipal.edu

DOI: $10.14260 /$ jemds/2016/1440

\section{(c) $($ ) $(9)$}

Multiple organs can be involved in alcohol toxicity like Hepatobiliary system, cardiovascular system, Central nervous system, Haemopoietic system. ${ }^{[4,5,6]}$ Literature survey shows that prolonged alcohol ingestion reduces the number of blood cell precursors causing structural abnormalities in these cells, resulting in lesser or non-functional mature blood cells.[7] Thus, alcoholics might suffer from moderate anaemia, characterised by enlarged, structurally abnormal RBCs, reduced numbers of WBCs, especially neutrophils; and reduced numbers of platelets. The resulting deficiency in RBC, WBC and platelets has numerous adverse consequences for the patient, including weakness, pallor and bleeding. Many times haematological changes are left undetected and untreated which could progress to cardiac failure. The present study was aimed to describe incidence and type of anaemia in alcoholics.

Alcohol - Related RBC Disorders.[8] Alcohol-related abnormalities in RBC production manifest themselves not only in the bone marrow but also through the presence of defective RBCs in the blood, grossly enlarged RBCs can occur in the blood - a condition called microcytosis - as well as oddly shaped RBCs that are subject to premature or accelerated destruction (i.e., haemolysis) because of their structural 
abnormalities. As a result, alcoholics frequently are diagnosed with anaemia.

\section{Macrocytosis}

The routine examination of blood samples from alcoholic and non-alcoholic patients using automated blood cell counters has resulted in the identification the mean corpuscular volume (MCV) - significantly larger than normal. However, an increased MCV does not automatically lead to a diagnosis of macrocytosis.

For example, cells with an increased MCV can be found in patients with folic acid or vitamin $\mathrm{B}_{12}$ deficiency (as in the case of megaloblastic anaemia) or with chronic liver disease Thus, the enlarged RBCs in patients with macrocytosis generally are uniformly round, in contrast to the more oval cells characteristic of megaloblastic anaemia. The increase in volume of human erythrocytes during chronic alcoholic intoxication and its decrease after alcoholic deprivation was studied with a multichannel analyser. When fractions of the population of red cells were separated by differential centrifugation the macrocytosis was found to be uniformly distributed.

The presence of macrocytes was not related to changes of plasma osmolality or hyperhydration of red cells. A central origin was evoked; however, the role of the folic acid deficiency could not explain the macrocytosis, the mechanism of which remains to be elucidated.

\section{Causes of Anaemia in Alcoholics}

Alcohol, as well as alcohol induced cirrhosis, leads to decreased red blood cell (RBC) production.

Hypersplenism, a condition characterised by an enlarged spleen and deficiency of one or more blood cell types, can induce premature RBC destruction. Blood loss occurs primarily in the gastrointestinal tract e.g., at the sites of peptic ulcers and is increased in patients with reduced platelet numbers.

Folic acid deficiency impairs RBC production and results from decreased ingestion, decreased absorption, and abnormal metabolism of folic acid.

- Hypersplenism.

- Blood loss.

- Liver disease.

- Folic acid deficiency.

- Reduced RBC production.

People who drink excessive amounts of alcohol can develop macrocytosis even in the absence of other factors associated with RBC enlargement, such as alcoholic liver disease or folic acid deficiency. Alcohol abuse is the most commonly associated with macrocytosis:

Up to 80 percent of men and 46 percent of women with macrocytosis have been found to be alcoholics.

Alcohol appears to interfere directly with RBC development, because the macrocytes disappear within 2 to 4 months of abstinence.

\section{Haemolytic Anaemia}

Haemolysis can be an underlying cause of anaemia, and several types of haemolytic anaemia may be caused by chronic heavy alcohol consumption. Two of these disorders are characterised by the presence of malformed RBCs- stomatocytes and spur cells-whereas one alcohol-related haemolytic anaemia is caused by reduced phosphate levels in the blood (i.e., hypophosphatemia).

Stomatocyte Haemolysis: Stomatocytes are RBCs with a defect in their membranes that causes the cells to assume a mouth or stoma-like shape. Stomatocytes have a shortened life span because they get trapped in the small capillaries of the spleen and are subsequently destroyed. In healthy people, stomatocytes account for less than 5 percent of the RBCs, whereas more than 25 percent of alcoholics exhibit an increased proportion of stomatocytes in the blood (i.e., stomatocytosis). Alcohol related liver disease may play a role in the development of stomatocyte haemolysis.

\section{Spur-Cell Haemolysis}

Spur cells are distorted RBCs that are characterised by spike like protrusions of their cell membrane. These spurs are caused by the incorporation of excess amounts of cholesterol into the cell membrane, resulting in an increase of the cell's surface area without a corresponding increase in cell volume. Spur cells may be prematurely eliminated in the spleen. Spurcell haemolysis occurs in about 3 percent of alcoholics with advanced liver disease, causing anaemia that progresses agents with cholesterol-lowering properties can be tried

However, most alcoholic patients with spur cell haemolysis are not acceptable candidates for major abdominal surgery, because their coexisting advanced liver disease increases their risk of bleeding. Moreover, the procedure may precipitate liver failure.

\section{Methods}

The present prospective cross sectional study comprised about 500 individuals comprising of 185 habitual consumers of alcohol and 315 non-consumers that served as controls. All the subjects were given questionnaire to determine the amount of alcohol they consume daily and the duration after which their blood samples were taken. Informed consent was obtained from the willing participants while unwilling consumers were excluded. Consumers of 4 bottles (of both beer and local gin)/day for a period of at least 5 years were chosen consumers and non-alcoholic drink consumers were taken as control. All subjects were healthy without any form of disease and with the age ranging from 19-50 years. About 5.0 $\mathrm{mL}$ blood sample from each subject was collected into $\mathrm{K}_{3}$ EDTA anticoagulant bottles and were analysed automatically for Packed Cell Volume (PCV), Haemoglobin estimation, Red cell count, total White Blood Cell Count (WBC), Platelet count, Mean Corpuscular Volume (MCV), Mean Corpuscular Haemoglobin (MCH) and Mean Corpuscular Haemoglobin Concentration (MCHC) using an autoanalyser (Sysmex KN$21 \mathrm{~N})$.

\section{MATERIALS AND METHODS}

Source of Data: Patients attending A. J. Institute of Medical Sciences, Mangalore.

\section{Method of Collection Data Samples Size}

1. 185 patients who consume alcohol.

2. 315 patients who doesn't consume alcohol.

3. 76 patients from non-alcoholics who are strict vegetarians. 


\section{Inclusion Criteria}

- All adult patients who are moderate alcoholics, that is, who consume 11 drinks per day or $80 \mathrm{~g}$ of alcohol three or four times a week.

- All patients who are severe alcoholics, that is, who consume more than 80 to $90 \mathrm{~g}$ of alcohol daily or more than 11 drinks per day.

- Patients who were admitted to the Medicine Ward in A. J. Institute of Medical Sciences, Mangalore.

- Adult patients who are non-alcoholics taken as control.

- Adult patients who consume vegetarian diet.

\section{Exclusion Criteria}

- All patients who are less than 18 years.

- Patients with bleeding disorders and history of chronic bleeding.

- Patients with chronic kidney diseases, chronic infections and malignancies.

\section{Study Design}

It is a prospective cross sectional study.

\section{Duration of Study}

Two years.

\section{Method of Analysis}

The data collected was analysed for descriptive statistical methods like frequency, distribution and association using Microsoft Excel, Worksheet and SPSS for Windows.

A standard clinical proforma was used to collect information from each adult patients.

The following Information was Collected from all Patients Admission and

1. Demography - Name, age, gender, occupation, socioeconomic status, date of admission and discharge.

2. Present History - Jaundice, pain abdomen, abdominal distention, bilateral pedal oedema, melaena, haematemesis, fever, altered sensorium and easy fatigability.

3. Alcoholic history - Amount of alcohol taken, number of days taken in a week.

4. Group - Moderate or severe or occasional.

5. Examination

a. General Physical Examination - Icterus, clubbing, pedal oedema, pallor, lymph nodes. Signs of liver cell failure like palmar erythema, loss of axillary hair, Dupuytren's contracture, parotid swelling, breast atrophy, testicular atrophy.

b. Systemic Examination - Per abdomen, Central nervous system, Respiratory System and Cardiovascular System were examined in detail by - inspection, palpation, percussion and auscultation.

6. Investigations - Information was collected for following investigations:

Complete blood count - Haemoglobin, red blood count, packed cell count, mean corpuscular volume, mean corpuscular haemoglobin, mean corpuscular haemoglobin concentration, total count, platelet count, peripheral blood smear.
7. Treatment History - Drugs used, dosage, duration, blood transfusion, ventilator support, gastroendoscopic interventions.

\section{RESULTS}

The mean haemoglobin in the present study was $10.46 \mathrm{~g} \%$ among alcoholics and $12.31 \mathrm{~g} \%$ among non-alcoholics (Table 1). $75 \%$ of the alcoholics had pallor (Table 2). The peripheral blood smear showed all types of anaemia (Table 3). Normocytic normochromic anaemia was present in $34 \%$ of patients. Next predominant was macrocytic hypochromic anaemia which was present in $26 \%$ of patients. Microcytic anaemia was present in $15 \%$ patients. Dimorphic anaemia was present in $17 \%$. However, even in non-alcoholics, $7 \%$ of patients also showed normocytic normochromic anaemia. $12 \%$ of non-alcoholics showed microcytic hypochromic anaemia. Thrombocytopenia was present in 5\% of alcoholics. Pancytopenia was present in $4 \%$ of patients.

\begin{tabular}{|c|c|c|}
\hline $\begin{array}{c}\text { Haemoglobin } \\
\text { Levels }\end{array}$ & $\begin{array}{c}\text { Moderate } \\
\text { Alcoholic } \\
(\mathbf{n}=92)\end{array}$ & $\begin{array}{c}\text { Severe } \\
\text { Alcoholic } \\
(\mathbf{n}=\mathbf{4 8})\end{array}$ \\
\hline$<10 \mathrm{~g}$ & $67(72.9 \%)$ & $38(79.1 \%)$ \\
\hline$>10 \mathrm{~g}$ & $25(27.1 \%)$ & $10(20.9 \%)$ \\
\hline \multicolumn{2}{|c|}{ Table 1. Haemoglobin Levels in Moderate and Severe } \\
Alcoholic Cases \\
\hline
\end{tabular}

\begin{tabular}{|c|c|c|}
\hline On Examination & Number (n=185) & \% \\
\hline Pallor & 137 & 74 \\
\hline Icterus & 118 & 64 \\
\hline Clubbing & 58 & 31 \\
\hline Pedal oedema & 76 & 41 \\
\hline Parotid Swelling & 34 & 18 \\
\hline Hepatomegaly & 108 & 58 \\
\hline Ascites & 97 & 52 \\
\hline \multicolumn{2}{|c|}{ Others } & 45 \\
\hline Table 2. Clinical Examination of Anaemia in Alcoholic \\
\hline
\end{tabular}

\begin{tabular}{|c|c|c|}
\hline $\begin{array}{c}\text { Peripheral Blood } \\
\text { Smear }\end{array}$ & $\begin{array}{l}\text { Alcoholics } \\
(n=185)\end{array}$ & $\begin{array}{c}\text { Non } \\
\text { Alcoholics } \\
(n=315)\end{array}$ \\
\hline $\begin{array}{c}\text { Normocytic } \\
\text { Normochromic } \\
\text { Anaemia }\end{array}$ & $13(7 \%)$ & $23(7 \%)$ \\
\hline Normal & $48(26 \%)$ & $197(63 \%)$ \\
\hline Macrocytic Anaemia & $48(26 \%)$ & $32(10 \%)$ \\
\hline $\begin{array}{l}\text { Microcytic hypochromic } \\
\text { Anaemia }\end{array}$ & $28(15 \%)$ & $37(12 \%)$ \\
\hline Dimorphic Anaemia & $32(17 \%)$ & $11(4 \%)$ \\
\hline Thrombocytopenia & $9(5 \%)$ & $10(4 \%)$ \\
\hline $\begin{array}{r}\text { Table 3. Compariso } \\
\text { Alcoholic an }\end{array}$ & riphera & $\begin{array}{l}\text { Smear in } \\
\text { tts }\end{array}$ \\
\hline
\end{tabular}

\section{DISCUSSION}

The present study showed that increased consumption has damaging effects ranging from severe infections to chances of bone marrow malfunctioning.

The present results are in accordance with the reports of the previous findings. $[9,10,11]$ Effects of alcohol on haematopoietic system are both direct and indirect. The direct effect of excessive alcohol consumption includes toxic effects on the bone marrow; the blood cell precursors; and the mature 
red blood cells, white blood cells and platelets. The indirect effect of alcohol includes nutritional deficiencies impairing the production and function of blood cells. These effects of alcohol can result in serious medical problems for the drinker. Decreased RBC causes fatigue, shortness of breath, lightheadedness, and even reduced mental capacity and abnormal heartbeats. A decrease in the number and function of WBCs increases the drinker's risk of serious infection, impaired platelet production leading to symptoms ranging from a simple nosebleed to bleeding to haemorrhagic stroke. Finally, alcohol-induced abnormalities in the plasma proteins that are required for blood clotting can lead to the formation of thrombosis.

Numerous clinical observations support the concept that alcohol adversely affects the production and function of virtually all types of blood cells. Thus, alcohol is directly linked to the toxicity of bone marrow, which contains the precursors of all blood cells, as well as to the mature cells circulating in the bloodstream. Long-term excessive alcohol consumption can hamper various physiological, biochemical, and metabolic processes involving the blood cells. The medical consequences of these adverse effects can be severe causing excessive bleeding and place the drinker at increased risk of strokes. These direct effects may be aggravated by the presence of other alcohol-related disorders, such as liver disease and nutritional deficiencies.

Based on the present result, we suggest that early detection of haematological changes in alcoholics and treating them can prevent further complications and helps in reducing the mortality. Physicians should study the haematological indices of their patients at an early stage before the complications of alcoholism is established.

\section{REFERENCES}

1. Das SK, Balakrishnan V, Vasudevan DM. Alcohol: its health and social impact in India. Natl Med J India 2006;19(2): 94-9.

2. Murray CJ, Lopez AD. Global mortality, disability and the contribution of risk factors: global burden of disease study. The Lancet 1997;349(9063):1436-42.

3. Rehm J, Rehn N, Room R, et al. The global distribution of average volume of alcohol consumption and patterns of drinking. Eur Addict Res 2003;9(4):147-56.

4. Vasudevan DM, Das SK, Mukherjee S. Non-alcoholic fatty liver diseases: an under recognized cause with emerging importance. Current Sci 2006;90(5):659-65.

5. Paton A. Asking the right questions. In: Paton A. 1994 ABC of alcohol. London: BMJ Publishing Group 1994:41.

6. Das KS, Balakrishnan V, Mukherjee S, et al. Evaluation of blood oxidative stress-related parameters in alcoholic liver disease and non-alcoholic fatty liver disease. Scand J Clin Lab Invest 2008;68(4):323-34.

7. Ballard HS. Hematological complications of alcoholism. Alcoholism Clinical and Experimental Research 1989;13(5):706-20.

8. Lynch SR. Interaction of iron with other nutrients. Nutr Rev 1997;55(4):102-10.

9. Ballard HS. Haematological complications of alcoholism. Alcohol Health Res World 1997;21(1):42-52.

10. Stanly PC, Wakwe VC, Ejele OA. Haematological profile in chronic alcohol consumers. Nigerian Journal of Clinical Practice 2003;6(2):84-6.

11. Peltz S. Severe thrombocytopenia secondary to alcohol use. Postgrad Med 1991;89(6):75-6, 85. 